\title{
Erratum
}

\section{Serum protein profiling by SELDI mass spectrometry: detection of multiple variants of serum amyloid alpha in renal cancer patients}

Jonathan Tolson, Ralf Bogumil, Elke Brunst, Hermann Beck, Raimund Elsner, Andreas Humeny, Hartmut Kratzin, Martin Deeg, Markus Kuczyk, Gerhard A Mueller, Claudia A Mueller and Thomas Flad

Laboratory Investigation (2004) 84, 1220-1221. doi:10.1038/labinvest.3700140

Correction to: Laboratory Investigation (2004) 84, 845-856.

doi:10.1038/labinvest.3700097

Due to a publisher error, two figures were displayed incorrectly. The correct figures are shown below:

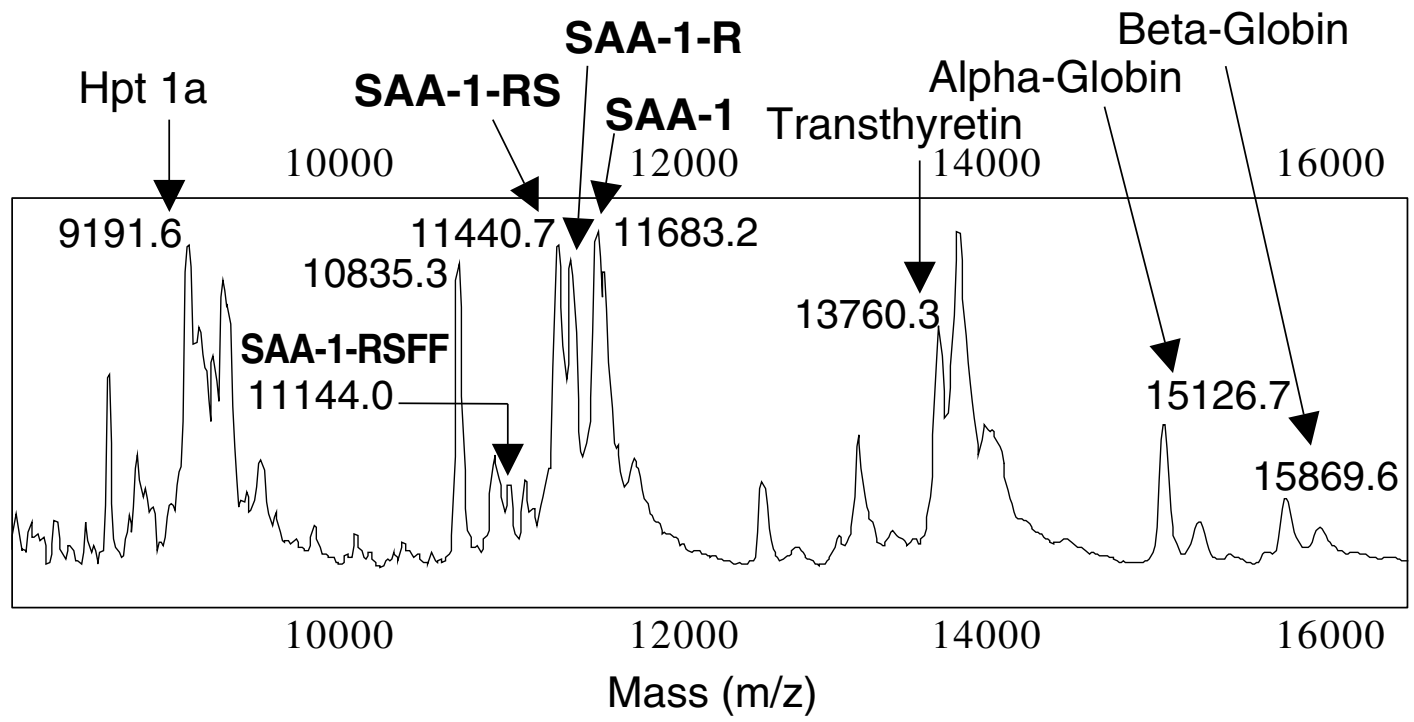

Figure 2 SELDI profile of patient R9 serum, using a laser intensity of 250. Proteins identified by in-gel tryptic digestion and peptide mapping are labelled and fit accurately to the expected average masses as given in Table 1 . The RCC-related protein at $\mathrm{m} / \mathrm{z}=10835.3 \mathrm{Da}$ remains unidentified. The peak corresponding to SAA-1 des-R occurs at $\mathrm{m} / \mathrm{z}=11526.5$. 


\section{RSFFSFLGEAFDGAR...}

SAA-2, spot 3

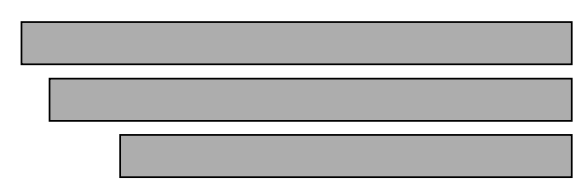

SAA-1, spot 1

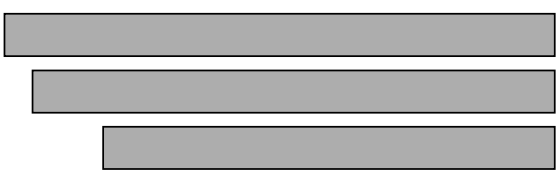

SAA-1, spot 2

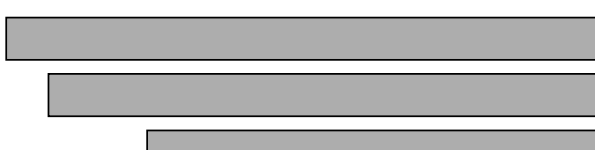

\section{Expected mass \\ of full length protein on SELDI}
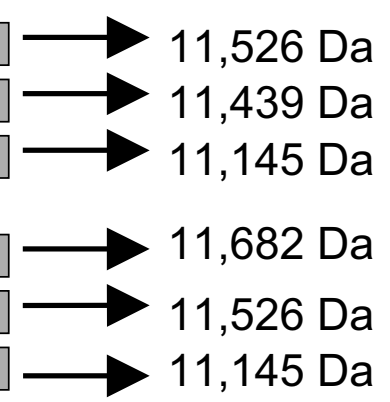

Figure 5 N-terminal sequences of SAA-1 and SAA-2 from 2-D electrophoresis as determined by in-gel tryptic digestion and measurement by MALDI Re-TOF mass spectrometry. All fragments terminated at arginine 15, the expected tryptic cleavage site. Of note are the two peptides spanning positions 3-15 (spots 1 and 3) and 5-15 (spots 1, 2 and 3), which correspond to uncommon N-terminal posttranslationally modified variants of SAA-1 visualized simultaneously by SELDI (Figure 3). Expected masses are given of the full-length protein variant. 